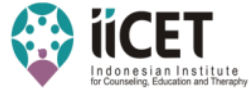

Dipublikasikan oleh:

Indonesian Institute for Counseling, Education and Therapy (IICET)

\title{
The effect of using cooperative learning model type of examples non examples and motivation toward student learning outcomes
}

\author{
Aulia Rahuma', Azwar Ananda ${ }^{2}$ \\ ${ }^{1}$ Social Studies Education Program, Postgraduate Program, At Universitas Negeri Padang, Indonesia \\ ${ }^{2}$ Universitas Negeri Padang
}

\begin{abstract}
This research aims to find out : (1) the differences outcomes learning of the social student subject between student taught by using example non example model and student taught by using convensional model (2) the differences outcomes learning of the social student subject between student taught by using example non example model with convensional models by looking from leaarning motivation. (3) the influence of interaction between example non example models with convensional models. This study is an experimental research (qasi-experiment) with a 2x2 factorial design. Analysis data in this research was use anava statistical test. Research finding suggest that : (1) there are differences outcomes learning of the social student subject between student taught by using example non example model and student taught by using convensional models (2) the students which have high motivation in learning that given by example non example models socialstudent subject are higher than convensional models students. (3) the students which have low motivation in learning outcomes learning of the social student are higher given by using conventional models than use example non example models. (4) there is an influence of interaction between example non example models with convensional models with learning motivation ( high - low) on the result of social student subject.
\end{abstract}

Key words : model example non example, convensional learning, learning motivation (high - low ), learning outcomes.

This is an open access article distributed under the Creative Commons Attribution License, which permits unrestricted use, distribution, and reproduction in any medium, provided the original work is properly cited. C2018 by author

\section{PENDAHULUAN}

Mata pelajaran IPS merupakan sebuah nama mata pelajaran integrasi dari mata pelajaran sejarah, geografi, dan ekonomi serta mata pelajaran ilmu sosial lainnya. Ciri mata pelajaran IPS sebagai mata pelajaran pada jenjang pendidikan dasar dan menengah adalah sifatnya terpadu (integrated) dari sejumlah mata pelajaran dengan tujuan agar pembelajaran lebih bermakna bagi peserta didik sehingga pengorganisasian materi/bahan pelajaran disesuaikan dengan (Sapriya, 2012: 7-8).

Pembelajaran IPS dilakukan agar terjadinya penyederhanaan dari berbagai disiplin ilmu yang ada. Hal ini karena pembelajaran IPS tersebut dapat dijelaskan dan dipahami dengan baik oleh siswa sehingga tujuan pembelajaran menjadi sesuai dengan yang diharapkan. Proses belajar mengajar merupakan inti dari proses pendidikan formal dengan guru sebagai pemegang peran utamanya. Mengajar pada hakekatnya adalah melakukan kegiatan belajar sehingga kegiatan belajar mengajar dapat berlangsung secara efektif dan efisien.

Motivasi belajar adalah proses yang memberi semangat belajar, arah dan kegigihan perilaku. Artinya perilaku yang termotivasi adalah perilaku yang penuh energi, terarah bertahan lama. Hakikat motivasi belajar adalah dorongan internal dan eksternal pada peserta didik yang sedang belajar untuk mengadakan perubahan perilaku (Suprijono, 2013: 163). 
Pembelajaran tidak berada pada satu arah saja di mana guru yang memberikan pengetahuan kepada siswa, namun juga siswa harus berperan aktif secara nyata agar tujuan pembelajaran sesuai dengan apa yang diharapkan. Keaktifan siswa tentunya berdasar pada motivasi yang dimiliki siswa untuk mendapat pelajaran di kelas.

Pengamatan awal yang dilakukan peneliti pada tanggal 12 Juli 2018 di SMP Pembangunan Laboratorium UNP, masih terlihat siswa yang kurang termotivasi dalam belajar. Hal ini dapat dilihat bahwa siswa di dalam kelas masih banyak tidak mendengarkan apa yang guru jelaskan di depan kelas. Dengan demikian dapat diidentifikasi bahwa siswa rendah dalam motivasi belajarnya sehingga akan berdampak pada hasil belajar. Berdasarkan wawancara oleh guru bidang studi IPS menjelaskan bahwa siswa tidak termotivasi belajar dikarenakan terjadinya proses perubahan dari anak-anak menuju dewasa karena anak-anak terlihat masih kurang memahami pentingnya belajar di dalam kelas. Pembelajaran di dalam kelas dianggap siswa bukanlah kebutuhan yang harusnya siswa serius untuk belajar sehingga siswa banyak tidak memperhatikan pembelajaran dengan baik. berikut adalah gambaran awal dari motivasi belajar siswa SMP Pembangunan Laboratorium UNP.

Berdasarkan apa yang diamati, peneliti juga melihat hasil rata-rata kelas siswa masih dibawah standar minimum yang ditentukan. Hal ini akibat dari siswa kurang bersemangat selama proses pembelajaran berlangsung, kurangnya motivasi dari siswa seperti tidak ingin memberikan pendapatnya secara berani dan rendahnya kepercayaan diri siswa. Model pembelajaran juga merupakan salah satu faktor yang menyebabkan siswa tidak termotivasi belajar karena pembelajaran masih terjadi hanya pada satu arah saja, di mana pembelajaran masih berpusat pada guru, dan siswa menerima apa yang disampaikan guru di kelas.

Sebagaimana diketahui jika motivasi belajar siswa tidak digerakkan atau dibangkitkan dengan baik, maka akan berdampak pada hasil belajar siswa, meskipun sekolah mendukung pembelajaran dengan baik seperti kelengkapan sarana prasarana, namun jika motivasi belajar siswa tidak meningkat maka tidak akan terjadi pembelajaran yang optimal sehingga tidak tercapainya tujuan pembelajaran dengan baik. terkait permasalahan siswa pada hasil belajar yang masih rendah maka perlu di perbaiki kembali apa yang membuat motivasi siswa menjadilebih baik lagi kedepannya.

Model pembelajaran yang dapat membangun motivasi siswa agar mendapat hasil belajar sesuai tujuan yaitu dengan menggunakan model pembelajaran kooperatif tipe Examples Non Examples. Menurut Aris Shoimin (2014: 74) pembelajaran kooperatif model Examples Non Examples memberi ruang dan kesempatan yang luas kepada setiap anggota kelompok untuk bertatap muka saling memberikan informasi dan saling membelajarkan. Interaksi tatap muka akan memberikan pengalaman yang berharga kepada setiap anggota kelompok untuk bekerja sama, menghargai setiap perbedaan, memanfaatkan kelebihan masing-masing anggota dan mengisi kekurangan masing-masing.

\section{METODE}

Penelitian ini dilakukan dengan menggunakan metode eksperimen. Jenis penelitian yang dilakukan adalah eksperimen semu (quasi eksperiment). Pengguanan penelitian quasi eksperiment untuk mengetahui pengaruh penggunaan model pembelajaran Examples Non Examples dan motivasi terhadap hasil belajar siswa pada mata pelajaran IPS kelas VII SMP Pembangunan Laboratorium UNP.

Desain factorial 2x2 digunakan sebagai desain pada penelitian ini. (Dantes, 2012: 100) Faktorial 2x2 adalah desain dasar faktorial yang dimaksud oleh Karlinger. Dalam desain faktoriral 2x2, perlakuan disusun sedemikian rupa sehingga setiap individu dapat menjadi subjek secara bersamaan dalam dua faktor yang berbeda yang setiap faktor terdiri atas beberapa level.

Berikut adalah tabel desain factorial, yaitu:

Tabel 1. Desain factorial $2 \times 2$

Motivasi Belajar Siswa Model Pembelajaran

Model Examples Non Examples $\left(\mathrm{A}_{1}\right) \quad$ Model Diskusi $\left(\mathrm{A}_{2}\right)$

\begin{tabular}{lcc} 
Tinggi $\left(\mathbf{B}_{1}\right)$ & $\mathrm{A}_{1} \mathrm{~B}_{1}$ & $\mathrm{~A}_{2} \mathrm{~B}_{1}$ \\
Rendah $\left(\mathbf{B}_{2}\right)$ & $\mathrm{A}_{1} \mathrm{~B}_{2}$ & $\mathrm{~A}_{2} \mathrm{~B}_{2}$ \\
\hline
\end{tabular}


Keterangan:

$\mathrm{A}_{1} \mathrm{~B}_{1}$ : rata-rata hasil belajar siswa yang diajarkan dengan model pembelajaran Examples Non Examples yang memiliki motivasi tinggi.

$\mathrm{A}_{2} \mathrm{~B}_{1} \quad$ : rata-rata hasil belajar siswa yang diajarkan dengan model pembalajran diskusi yang memiliki motivasi belajar tinggi.

$\mathrm{A}_{1} \mathrm{~B}_{2} \quad$ : rata-rata hasil belajar siswa yang diajarkan dengan model pembelajaran Examples Non Examples yang memiliki motivasi belajar rendah.

$\mathrm{A}_{2} \mathrm{~B}_{2}$ : rata-rata hasil belajar siswa yang diajarkan dengan model pembelajaran diskusi yang memiliki motivasi rendah.

\section{HASIL DAN PEMBAHASAN}

Dari hasil perhitungan untuk taraf kepercayaan $\alpha=0,05$ terlihat bahwa nilai Lhitung untuk semua kelompok lebih kecil daripada Ltabel. Dengan demikian dapat disimpulkan bahwa data Hasil belajar IPS dari semua kelompok data I, II, III, IV, V, VI, VII dan VIII adalah berasal dari populasi yang berdistribusi normal. Untuk lebih jelasnya hasil uji tersebut secara keseluruhan dapat dilihat pada Tabel 4.10 di bawah ini.

Tabel 3: Rekapitulasi Hasil Pengujian Normalitas Data

\begin{tabular}{ccccc}
\hline $\begin{array}{c}\text { Kelompok } \\
\text { Sampel }\end{array}$ & $\begin{array}{c}\text { Jumlah } \\
\text { Sampel }\end{array}$ & $\mathbf{L}_{\text {hitung }}$ & $\mathbf{L}_{\text {tabel }}$ & Kesimpulan \\
I & 14 & 0,182 & 0,227 & Normal \\
II & 14 & 0,194 & 0,227 & Normal \\
III & 14 & 0,181 & 0,227 & Normal \\
IV & 14 & 0,153 & 0,227 & Normal \\
V & 7 & 0,195 & 0,300 & Normal \\
VI & 7 & 0,214 & 0,300 & Normal \\
VII & 7 & 0,124 & 0,300 & Normal \\
VIII & 7 & 0,165 & 0,300 & Normal \\
\hline
\end{tabular}

Uji homogenitas menggunakan uji Barlet dilakukan terhadap (a) dua kelompok perlakuan A1 dan A2, (b) dua kelompok atribut B1 dan B2, dan (c) empat kelompok sel dalam rancangan eksperimen A1B1, A1B2, A2B1 dan A2B2.Pengujian homogenitas varians melalui pendekatan $\chi 2$ dengan kriteria pengujian terima Ho jika $\chi 2$ hitung $<\chi 2$ tabel yang berarti varians homogen dan tolak Ho jika $\chi 2$ hitung $\geq \chi 2$ tabel yang berarti varians tidak homogen. Diuji pada taraf kepercayaan $\alpha=0,05$; $\mathrm{dk}=\mathrm{k}-1$.

Hasil perhitungan dan uji signifikan varians masing-masing kelompok data tersebut dapat dirangkum pada tabel 4.11 di bawah ini:

Tabel 4: Hasil Uji Homogenitas Varians Kelompok Data

$\begin{array}{cccc}\text { Kelompok } & \chi^{2} \text { hitung } & \chi^{2} \text { tabel } & \text { Kesimpulan } \\ \mathrm{A}_{1} \text { dan } \mathrm{A}_{2} & 5.40 & 38.89 & \text { Homogen } \\ \mathrm{B}_{1} \text { dan } \mathrm{B}_{2} & 7.95 & 38.89 & \text { Homogen } \\ \mathrm{A}_{1} \mathrm{~B}_{1}, \mathrm{~A}_{2} \mathrm{~B}_{1}, \mathrm{~A}_{1} \mathrm{~B}_{2}, \mathrm{~A}_{2} \mathrm{~B}_{2} & 2.13 & 36.42 & \text { Homogen }\end{array}$

Dari tabel di atas terlihat bahwa nilai $\chi^{2}$ hitung dari ketiga kelompok data lebih kecil dari $\chi 2$ tabel pada taraf kepercayaan $\alpha=0,05$. hal ini berarti bahwa keseluruhan kelompok data yang diuji memiliki varians yang homogen.

Hasil pengujian normalitas dan homogenitas data tersebut menunjukkan bahwa kelompok-kelompok data dalam penelitian ini berasal dari populasi yang berdistribusi normal dan memiliki varians yang homogen. Dengan demikian maka persyaratan normalitas dan homogenitas data terpenuhi sehingga dapat digunakan Analisis Varians (ANAVA) dalam pengujian hipotesis penelitian. 
Hasil-hasil pengujian hipotesis dapat dirangkum dalam tabel 4.12 di bawah ini:

Tabel 4:Tabel ANAVA Dua Jalur

\begin{tabular}{|c|c|c|c|c|c|c|c|}
\hline \multirow[t]{2}{*}{ Sumber Varians } & \multirow[t]{2}{*}{ JK } & \multirow[t]{2}{*}{ db } & \multirow[t]{2}{*}{ RJK } & \multirow[t]{2}{*}{$\mathbf{F}_{\text {hitung }}$} & \multicolumn{2}{|c|}{$\mathbf{F}_{\text {tabel }}$} & \multirow[t]{2}{*}{ Ket } \\
\hline & & & & & $\mathrm{a}=0,05$ & $\mathbf{a}=0,01$ & \\
\hline Metode Pembelajaran & 1026,87 & 1 & 1026,87 & 10.07 & 4.20 & 7.64 & sangat signifikan \\
\hline Motivasi belajar & 1026,87 & 1 & 1026,87 & 10.07 & 4.20 & 7.64 & sangat signifikan \\
\hline Inter AB & 2512,15 & 1 & 2512,15 & 24.64 & 4.20 & 7.64 & sangat signifikan \\
\hline Kekeliruan Dalam & 2446,66 & 24 & 101,94 & - & - & - & \\
\hline Total & 7012,56 & 27 & & - & - & - & \\
\hline
\end{tabular}

$\rho<0,05 ; * * \rho<0,01$

Adanya interaksi dan signifikannya pengaruh utama antara model pembelajaran dan Motivasi belajar dalam analisis varians di atas maka pengujian dilanjutkan dengan menggunakan uji Tukey antara pasangan data guna menentukan rata-rata kelompok mana yang lebih tinggi antara dua kelompok data yang dipasangkan.

Tabel 5 : $\quad$ Tabel Hasil Uji Tukey antara Kelompok Data

\begin{tabular}{cccccc}
\hline Kelompok & $\mathrm{N}$ & $\mathrm{Q}_{\text {hitung }}$ & \multicolumn{2}{c}{$\mathrm{Q}_{\text {tabel }}$} & Kesimpulan \\
& & & $\alpha=0,05$ & $\alpha=0,01$ & \\
$\mathrm{~A}_{1}-\mathrm{A}_{2}$ & 28 & $10,99^{* *}$ & 2,89 & 3,89 & Sangat Signifikan \\
$\mathrm{B}_{1}-\mathrm{B}_{2}$ & 28 & $10,99^{* *}$ & 2,89 & 3,89 & Sangat Signifikan \\
$\mathrm{A}_{1} \mathrm{~B}_{1}-\mathrm{A}_{2} \mathrm{~B}_{1}$ & 14 & $19,93^{* *}$ & 3,03 & 4,21 & Sangat signifikan \\
$\mathrm{A}_{1} \mathrm{~B}_{2}-\mathrm{A}_{2} \mathrm{~B}_{2}$ & 14 & $4,39 * *$ & 3,03 & 4,21 & Sangat Signifikan \\
\hline
\end{tabular}

Keterangan :

**) = sangat signifikan

*) $=$ signifikan

Hasil pengujian hipotesis membuktikan bahwa Hasil belajar IPS siswa pada kedua perlakuan memberikan perbedaan yang sangat signifikan. Dan melalui uji lanjut terbukti bahwa Hasil belajar IPS siswa yang diberi perlakuan pembelajaran kooperatif tipe Examples Non Exampleslebih tinggi dibandingkan dengan siswa yang diberi perlakuan Pembelajaran konvensional Hasil pengujian pengaruh Motivasi belajar siswa juga menunjukkan adanya perbedaan yang signifikan antara kelompok siswa yang memiliki Motivasi belajar tinggi dengan siswa yang memiliki Motivasi belajar rendah. Hasil belajar IPS siswa yang memiliki Motivasi belajar tinggi lebih tinggi dibandingkan dengan Hasil belajar IPS siswa yang memiliki Motivasi belajar rendah.Efektifitas model pembelajaran dengan pembelajaran kooperatif tipe Examples Non Examples pada kelompok siswa yang memiliki motivasi belajar tinggi, terkait dengan sifat subjek siswa dan model interaksi pembelajaran yang tercipta oleh pembelajaran kooperatif tipe Examples Non Examplesitu sendiri.

Sebaliknya pada siswa yang memiliki Motivasi belajar rendah, penggunaan Pembelajaran konvensional mencapai hasil yang lebih tinggi jika dibandingkan dengan penggunaan pendekatan pembelajaran secarakooperatif tipe Examples Non Examples. Hal ini memberikan pemahaman bahwa bagi siswa yang mempunyai Motivasi belajar rendah, terkait dengan sifat subjek siswa dan pendekatan interaksi Pembelajaran konvensional itu sendiri.

\section{KESIMPULAN}

Berdasarkan hasil pengujian hipotesis berikut pembahasannya, dapat disimpulkan temuan penelitian sebagai berikut: (1) Secara keseluruhan, hasil belajar IPS siswa yang diberi perlakuan Pembelajaran kooperatif tipe Examples Non Examples lebih tinggi dari Hasil belajar IPS siswa yang diberi Pembelajaran konvensional; (2) Untuk siswa yang memiliki Motivasi belajar tinggi, hasil belajar IPS bagi siswa yang diberi perlakuan Pembelajaran kooperatif tipe Examples Non Examples lebih tinggi dari siswa yang diberi Pembelajaran 
konvensional; (3) Untuk siswa yang memiliki Motivasi belajar rendah, hasil belajar IPS bagi siswa yang diberi Pembelajaran konvensional, lebih tinggi dari yang diberi perlakuan Pembelajaran kooperatif tipe Examples Non Examples; (3) Terdapat pengaruh interaksi antara Pembelajaran kooperatif tipe Examples Non Examples dan pembelajaran konvensional dengan Motivasi belajar (tinggi dan rendah) terhadap hasil belajar IPS siswa.

\section{DAFTAR RUJUKAN}

Arikunto, Suharsimi. (2006). Prosedur Penelitian Suatu Pendekatan Praktik. Jakarta: PT Asdi Mahastya.

Aritonang, K. T. (2008). Minat dan motivasi dalam meningkatkan hasil belajar siswa. Jurnal Pendidikan Penabur, 7(10), 11-21.

Asma, Nur. (2012). ModelPembelajaran Kooperatif. Padang: UNP Press.

B. Uno, Hamzah dan Nurdin Mohamad. (2013). Belajar dengan Pendekatan PAILKEM (Strategi Pembelajaran PAILKEM Merupakan Salah Satu Strategi yang dapat Diterapkan ungutk Mengoptimalkan Kegiatan Pembelajaran Di Sekolah). Jakarta: Bumi Aksara.

B. Uno, Hamzah.(2009). Teori Motivasi dan Pengukurannya: Analisis Bidang Pendidikan. Jakarta: Bumi Aksara.

B. Uno. Hamzah dan Satria Koni. (2012). Assessment Pembelajaran. Jakarta: Bumi Aksara.

Dantes, Nyoman. (2012). Metode Penelitian. Yogyakarta: ANDI.

Hamalik, Oemar. (2008). Proses Belajar Mengajar. Jakarta: Bumi aksara.

Huda, Miftahul. (2011). Cooperative Learning: Metode, Teknik, Struktur dan Modal Penerapan. Yogyakarta: Pustaka Pelajar.

Huda, Miftahul. (2014). Model-Model Pengajaran dan Pembelajaran: Isu-Isu Metodis dan Paradigmatis. Yogyakarta: Pustaka Pelajar.

Irianto, Agus. (2009). Statistik Konsep Dasar dan Aplikasinya. Jakarta : Kencana.

Isjoni. (2013). Pembelajaran Kooperatif: Meningkatkan Kecerdasan Komunikasi Antar Peserta Didik. Yogyakarta: Pustaka Pelajar.

Manurung, I. W., Mulyani, B., \& Saputro, S. (2013). Pengaruh Penggunaan Model Pembelajaran Kooperatif Numbered Head Together (Nht) Dan Learning Together (Lt) Dengan Melihat Kemampuan Memori Siswa Terhadap Prestasi Belajar Siswa Pada Materi Tata Nama Senyawa Kimia Kelas X SMA Negeri 2 Karanganyar. Jurnal Pendidikan Kimia, 2(4), 24-31.

Mappeasse, M. Y. (2009). Pengaruh cara dan motivasi belajar terhadap hasil belajar programmable logic controller (PLC) siswa kelas III jurusan listrik SMK Negeri 5 Makassar. Jurnal Medtek, 1(2), 1-6.

Muri Yusuf, A. (2007). Metode Penelitian. Padang: UNP Press.

Nurhadi, dkk. (2004). Pembelajaran Konstektual (Contectual Teaching and Learning/CTL) dan penerapannya dalam KBK. Malang: UniversitasNegeri Malang.

Purwanto. (2011). Evaluasi Hasil Belajar. Yogyakarta: Pustaka Pelajar.

Rusman. (2012). Model-Model Pembelajaran (Mengembangkan Profesionalisme Guru). Jakarta: Rajawali Pers.

Sardiman. (2012). Interaksi dan Motivasi Belajar Mengajar. Jakarta: Rajawali Pers.

Shoimin, Aris. (2014). 68 Model Pembelajaran Inovatif dalam Kurikulum 2013. Yogyakarta: Ar-Ruzz Media.

Sjukur, S. B. (2012). Pengaruh blended learning terhadap motivasi belajar dan hasil belajar siswa di tingkat SMK. Jurnal Pendidikan Vokasi, 2(3).

Slameto. (2015). Belajar dan Faktor-Faktor yang Mempengaruhi. Jakarta: Rineka Cipta.

Sugiyono. (2012). Metode Penelitian Kuantitatif, Kualitatif, dan R \& D. Bandung: Alfabeta.

Sukandi, Ujang. (2003). Belajar Aktif dan Terpadu: Apa, Mengapa, dan Bagaimana. Surabaya: Duta Graha Pustaka.

Sumiati dan Asra. (2007). Metode Pembelajaran. Bandung: Wacana Prima.

Suprijono, Agus.(2009). Cooperative Learning.Surabaya: PustakaPelajar.

Suprijono, Agus. (2013). Cooperative Learning: Teori \& Aplikasi PAIKEM. Yogyakarta: Pustaka Pelajar.

Suryobroto, B. (2002). Proses Belajar Mengajar di Sekolah. Jakarta: Rineka Cipta.

Syah, Muhibbin. (2008). Psikologi Belajar. Jakarta: Raja Grafindo Persada.

Trianto, (2009).Mendesain model pembelajraninovatif-progresif. Jakarta: Kencanaprenada media group.

Undang-Undang Republik Indonesia Nomor 20 Tahun 2003 tentang Sistem Pendidikan Nasional. 2006. Jakarta: Arnas Duta Jaya.

Widodo, T. (2009). Metode Penelitian Kuantitatif. Surakarta: UNS Press.

Wulandari, I. S. (2014). Pengaruh Pemberian Reward and Punishment Terhadap Motivasi Belajar Siswa dalam Pembelajaran Passing Bawah Bolavoli (Studi pada Siswa Kelas VIII SMP Negeri 1 Yosowilangun Lumajang). Jurnal Pendidikan Olahraga dan Kesehatan, 2(3). 